\title{
Automated axial flow turbine design with performance prediction
}

\author{
Nader A. Elqussas ${ }^{1}$, Aly M. Elzahaby ${ }^{2}$, Mohamed K. Khalil ${ }^{3}$ and Ahmad M. Elshabka ${ }^{4}$ \\ ${ }^{1}$ Ph.D. Candidate, Armament and Ammunition Department, Military Technical College, Cairo \\ 2 Department of Mechanical Engineering, Faculty of Engineering, Tanta university, Tanta \\ ${ }^{3}$ Department of Aircraft Mechanical Engineering, Military Technical College, Cairo \\ ${ }^{4}$ Assistant Professor, Department of Aircraft Mechanical Engineering, Military Technical \\ College, Cairo, Egypt.
}

Original

Article

\section{Key words:}

Axial flow turbine design, axial flow turbine, axial turbine performance.

\section{Corresponding Author:}

Nader A. Elqussas, Ph.D. Candidate, Armament and Ammunition Department, Military Technical College, Egypt, Tel: +2035253049 .

Email: naderelqussas@yahoo.com.

\section{Abstract}

This paper describes the automation of preliminary 3D aerothermodynamic design and analysis of a single-stage axial flow turbine driving the compressor of the micro turbojet engine Jet Cat p200 using an analytical method. The geometrical parameters of the new design are based on the reverse engineering of the small gas turbine. Baseline stage dimensions and design parameters such as flow coefficient, stage loading factor are close to 0.5 and 1.14 , respectively, with maximum expansion in the NGV (stator) row. In the thermal cycle and 1D analysis calculations, the turbine flow path and the meanline total conditions of all engine stations and all design controlling parameters are determined on the basis of mass, energy and momentum conservation. The results are compared with the published data in the engine manual and gave a good match. The axially symmetric assumption changes the $3 \mathrm{D}$ flow problem through the turbine stage into $2 \mathrm{D}$ problem, i.e. the flow through the profile cascade. Applying the simple radial equilibrium approach at the axial gapes with selecting the free vortex law of blading, the velocity triangles at different radii along the blade length are determined. The generated velocity triangles are used to design the profile cascades considering parabolic mean, convex and concave sides. The turbine stage performance is calculated at design point and off-design conditions based on the one-dimensional analytical approach with constant total pressure loss coefficient across the stator and constant relative velocity recovery factor across the rotor. A CFD model is constructed to evaluate the turbine stage performance numerically. The CFD results are compared with that of the analytical method which give a good match.

\section{I- INTRODUCTION}

With the great evolution of commercial axial turbines design codes, the task of generating rapid and accurate design code for the turbine stage has become essential for any turbomachinery producer to minimize the cost in terms of both money and time ${ }^{[1]}$.

The code presented in this research is designed for a special methodology for designing an axial turbine stage $^{[2]}$. Such methodology includes 1D, 2D, and 3D calculation techniques in addition to a performance prediction code.

The real flow through the gas turbine is $3 \mathrm{D}$ viscous compressible flow with heat transfer. The 3D problem is changed to $2 \mathrm{D}$ problem through using the axially symmetric assumption (flow through the profile cascade), where the fluid properties are function of the axial and radial coordinates. By solving the flow field at the axial gaps between the blade cascades under the assumption of steady and ideal flow in cylindrical gas passages with heat transfer neglection, the simple radial equilibrium (SREE) is derived. To solve the flow field, the law of blading would be selected e.g. free vortex law of blading. As result, flow velocity variations along the blade length for both stator and rotor blade cascades are obtained. Having the velocity triangles at different radii enables us to design the profile cascades at each radius.

The design proceeds as follows:

-Data input collection (from the base engine data manual $)^{[3]}$

-Engine thermal cycle analysis.

-Aerothermodynamic calculations to determine the gas 
flow path through the turbine based on 1D mean streamline approximation.

-Assuming axially symmetric conditions, and applying the free vortex law of blading, the velocity triangles at different radii are determined.

-2D profile design along the blade length is done, where mean, convex and concave parabolic lines are selected.

-3D blade airfoil stacking is done for both stator and rotor blade cascades giving the $3 \mathrm{D}$ model of the turbine stage.

-A model of the flowing flow governing equations through the axial turbine stage is used to evaluate the turbine performance analytically based on the 1D analysis.

-A CFD model for the axial turbine stage with the real working conditions as the boundary conditions to evaluate the 3D flow through the turbine stage including stator and rotor blades.

- Numerical evaluation of turbine performance using CFD simulation.

-Comparison between the results of the two methods.

This design software has the capability to meet the comprehensive design requirements of any axial flow turbine stage with the prediction of its performance.

There are four sets of modules available in this code to carry out the $1 \mathrm{D} / 2 \mathrm{D} / 3 \mathrm{D}$ design and analysis. The Aerothermodynamic calculations and 1D module are used to determine the turbine dimensions with the given set of design requirements [4]. The through-flow calculation, 2D/3D modules are used for blade profile design and 3D flow analysis. The overall design process of a gas turbine engine usually starts with a given set of specifications, which normally determined by the market demands or by specific customer requirements. There are four principle steps involved in turbine aerodynamic design process: preliminary design using mean line approach, through flow design, airfoil design which is followed by losses and performance prediction module to calculate the turbine performance, finally a 3D CAD model is generated with CFD simulation process and analysis.

The performance of turbines is limited principally by stress and compressibility. Stresses limit the engine blade speed (engine RPM and blade length) and compressibility limits the mass flow that flows through the turbine (turbine chocking). The work delivered per stage, for example, depends on the square of the blade tip speed. The performance of the engine extremely depends on the maximum turbine inlet temperature. Therefore, as the maximum turbine inlet temperature increases, the allowable stress level decreases, hence in the design of the engine there must be a compromise between maximum turbine inlet temperature and maximum rotor blade tip speed [5].

As a case study, this design methodology is applied on the reverse engineering of the gas turbine stage of the JETCAT P200 turbojet engine. The engine dimensions mentioned in the official manual are used to verify the resultant data generated by the program code.
In this paper, an effort is made to carry out the aerothermodynamic design and performance analysis of a single axial flow gas turbine stage using the mentioned codes and redesign the blade profiles based on the analytical approach.

\section{II- ANALYTICAL PRELIMINARY DESIGN OF AXIAL TURBINE STAGE}

\section{II.I- Mean line 1D and 2D design}

The most important step of the preliminary design is to determine the design requirements. This involves a parametric study of the design requirements by choosing the flow coefficient, the stage loading coefficient, design total to total expansion ratio, total-to-total isentropic efficiency to get the desired performance. The preliminary mean line design is carried out in three phases. These are the geometric dimensions verification phase with the real object, redesign phase and the analysis phase.

\section{II.I.I- The geometric dimensions verification}

This phase involves the stage meridional plane and flow path design using inlet operating conditions of the turbine stage to match the actual geometric requirements. The design speed, mass flow rate, inlet total temperature and pressure and the all input data with full admission are considered. In this case study, number of stage is set to one. The flow path is constrained by constant hub and tip radius and limited by maximum hub/tip radius and inlet and exit swirl angles. The near optimum values of flow coefficient and load coefficient are determined and are close to 0.5 and 1.14, respectively. These design values are determined according to the optimum pitch-to-chord ratio of 1.33 at mean line.

During this section, the aerothermodynamic parameters of the fluid flow, the gas path dimensions, the different dimensionless groups and the velocity triangles are determined using a predesigned MATLAB code.

To start the determination of gas flow parameters at different engine sections, it is assumed that, the engine is working at standard conditions.

The total flow parameters at different engine modules are obtained by solving the Continuity, Energy and Momentum equations. Fig. 1 illustrates a schematic drawing for the studied engine.

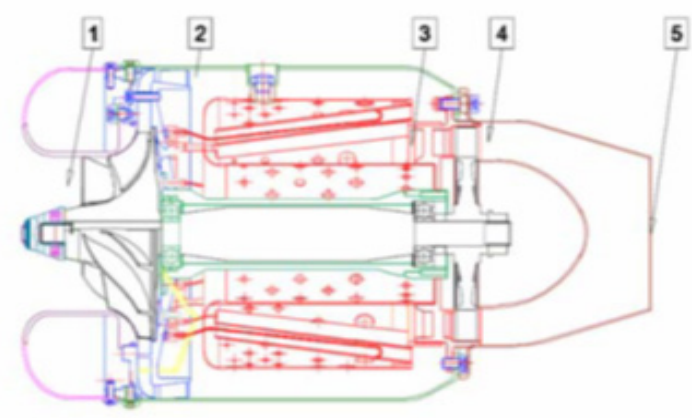

Fig. 1: JETCAT P200 schematic drawing 
The generated aerodynamic data from this module of the MATLAB code is illustrated in Table 1.

Table 1: Thermal cycle data.

\begin{tabular}{lcc}
\hline & $\begin{array}{c}\text { Total temperature } \\
(\mathrm{K})\end{array}$ & $\begin{array}{c}\text { Total pressure } \\
(\mathrm{Pa})\end{array}$ \\
\hline Compressor inlet & 288 & 100306.8 \\
Compressor outlet & 474.62 & 401227.2 \\
Turbine inlet & 1177.67 & 385016 \\
Turbine outlet & 1023 & 193685.78 \\
\hline
\end{tabular}

The resultant data from this step is used to determine the different dimensionless groups like the mass flow and the specific speed groups.

Solving the flow governing equations generates the main dimensions of the turbine stage meridional plane as shown in table 2 and Fig. 2.

At the end of this phase, engine design speed and all dimensions of the meridional plane are determined and verified with real one and gave a good match.

Table 2: Meridional plane data.

\begin{tabular}{lcc}
\hline & Dimension & Unit \\
\hline Hub radius & 29.8 & $\mathrm{~mm}$ \\
Mean radius & 35.7125 & $\mathrm{~mm}$ \\
Tip radius & 41.625 & $\mathrm{~mm}$ \\
Actual chord & 8.5 & $\mathrm{~mm}$ \\
Blade cascade width & 7 & $\mathrm{~mm}$ \\
\hline
\end{tabular}

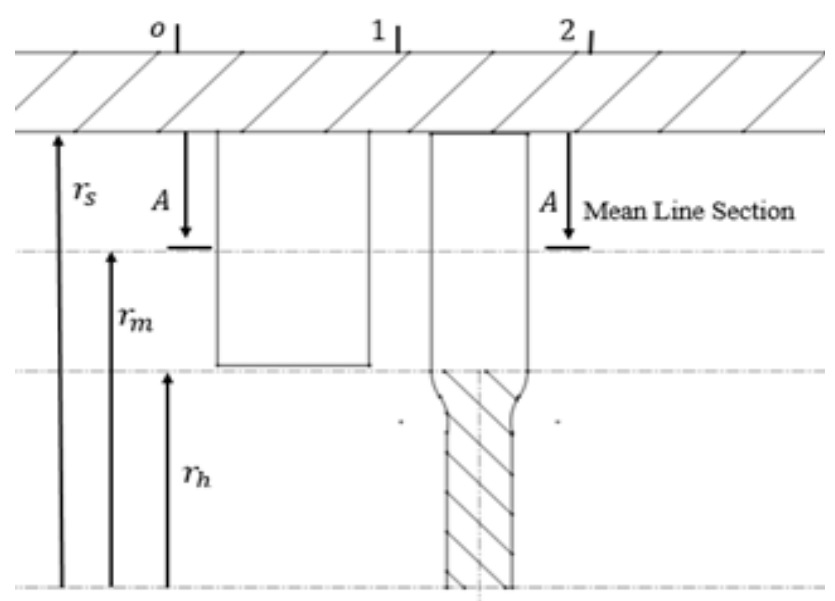

Fig. 2: The meridional plane of the axial turbine stage.
The predicted meanline profile cascade for the turbine stage is shown in Fig. 3 in terms of the flow parameters.

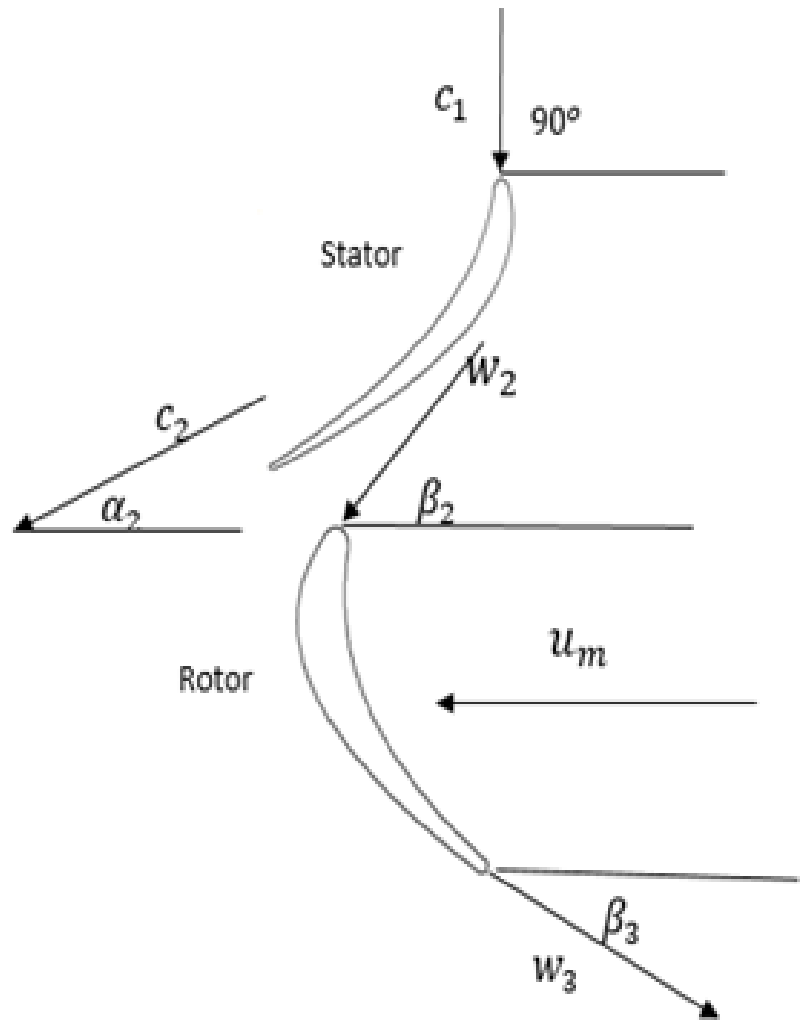

Fig. 3: Rotated A-A section

\section{II.I.II- 2D flow field determination}

The mean streamline design approach is the basic concept for 2D airfoil preliminary design and performance prediction in an axial flow turbine design process.

The preliminary design of the axial flow turbine stage is done using a special MATLAB code is designed on the basis of the conservation of mass and momentum from inlet to exit using the reduced order and throughflow mean streamline approach.

As the flow aerothermodynamic parameters are determined, this design phase can be done as follows ${ }^{[2]}$ :

1. A model of four equations (energy, momentum, mass flow rate and the universal low of gases) is ready to be constructed and solved at the turbine stage entry whereas, the inlet gas flow velocity to the turbine stage is calculated.

2. Assuming the nozzle row exit blade angle varies within the range of $\alpha_{2}=\left(18^{0}-32^{\circ}\right)$

3 . At this point, the absolute gas angle entering the rotor blade row is determined with maximum expansion in the nozzle row and therefore, by knowing the blade speed, the velocity triangle at the rotor entry is determined, Fig. 4.

4. Applying the power needed from the turbine to calculate the exit velocity triangle using Euler's equation based on Rothalpy conservation.

5. This process is repeated until having minimum exit absolute swirl angle to insure minimum losses.

6. Using the free vortex law of blading to generate the 
velocity triangles at different sections along the rotor blade span from hub to tip.

Fig. 4 shows the velocity triangles at inlet and exit of the rotor blade mean line

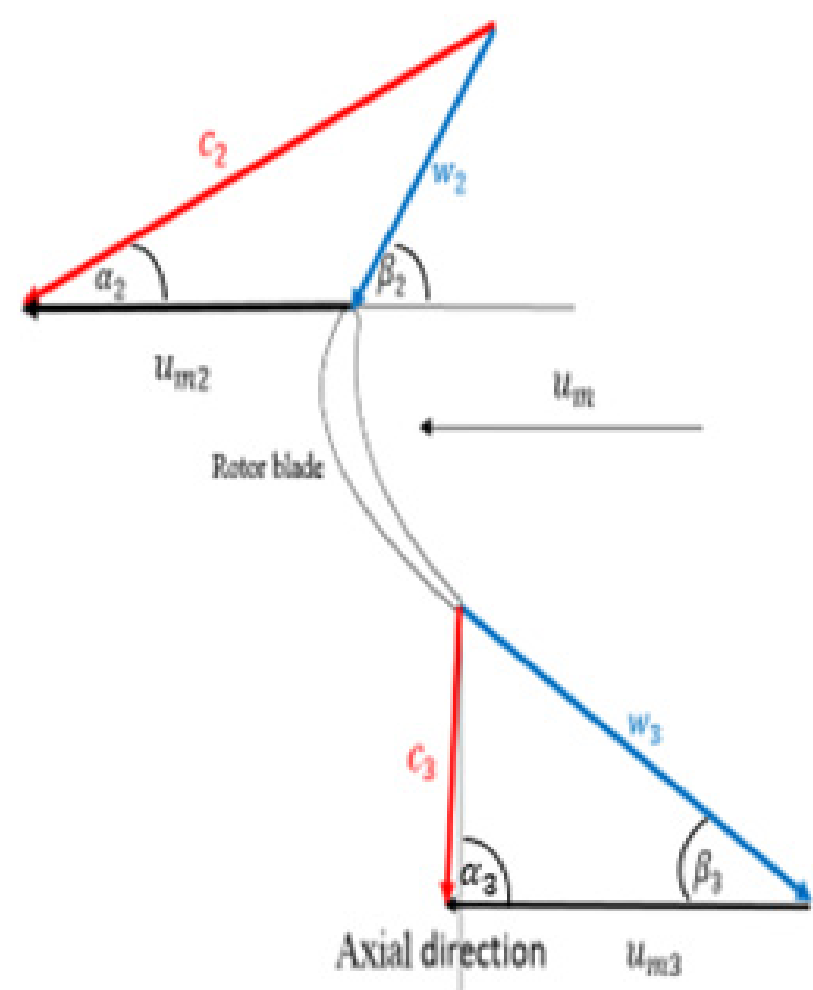

Fig. 4: The generated inlet and exit velocity triangles at rotor mean line

Fig. 5 shows the rotor inlet velocity triangles at root, mean line and tip for the rotor blade.

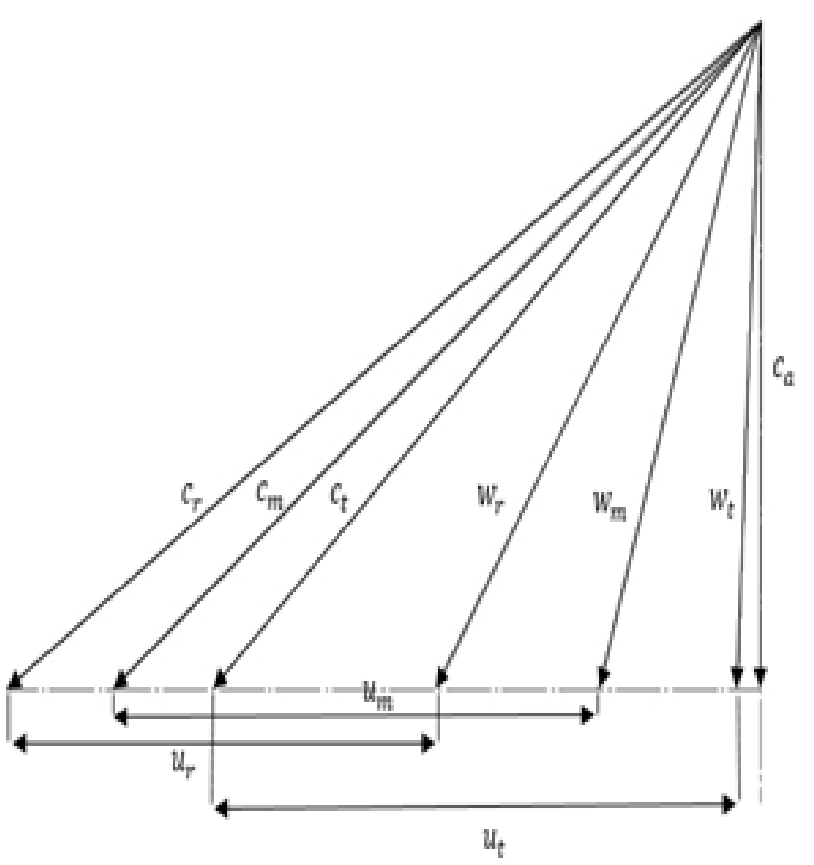

Fig. 5: Rotor inlet velocity triangles at hub, mean and tip sections.

\section{II.I.III- Redesign of the profile cascades}

For profile design, mean, convex and concave parabolic lines are selected. At first, the meanline is drawn where the inlet and the exit relative flow velocities are tangent to its entry and exit, respectively. The thickness distribution of the profiles along the meanline line is controlled by selecting leading edge radius, trailing edge thickness and leading and trailing edge geometric angles.

Using the real blade aspect ratio of the JETCAT P 200 , the stator and rotor mean line airfoils are designed graphically in terms of the generated data from the previous phase of design using the quadratic Beizier spline fit curves $^{[6]}$ to generate the material distribution of the airfoil as shown in Fig. 6. for stator and Fig. 7. for rotor. The blade airfoil is divided into four sections, which are (leading edge, pressure side, trailing edge and suction side) ${ }^{[7]}$. The turbine stage has 22 stator blades and 29 rotor blades. The rotor blade has a constant hub and tip radius with a hub to tip ratio of 0.7 while the blade length is 12 $\mathrm{mm}$. The width of the axial turbine stage is about $40 \mathrm{~mm}$. To generate the blade 3D shape, this process is repeated to obtain the airfoils at different radii

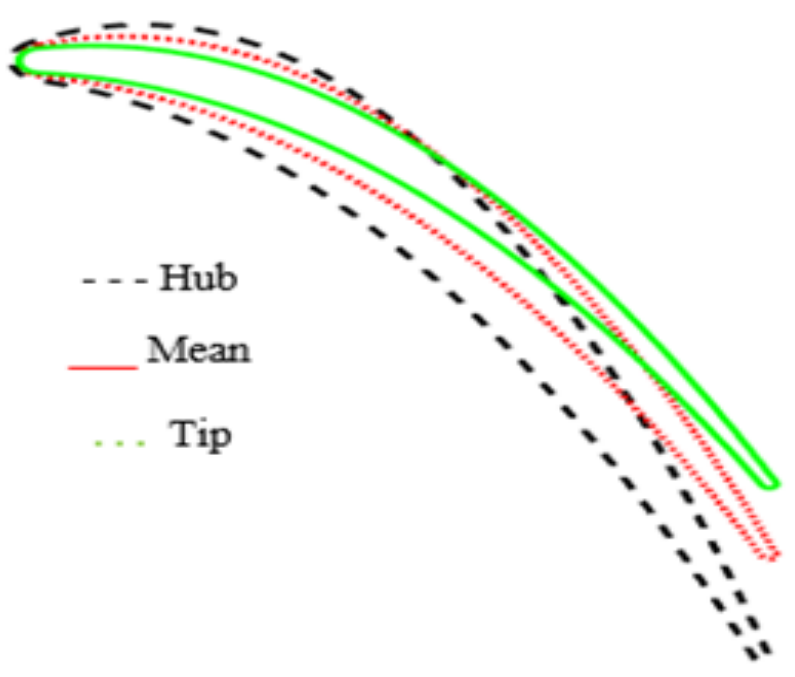

Fig. 6: The generated airfoil sections for stator blade

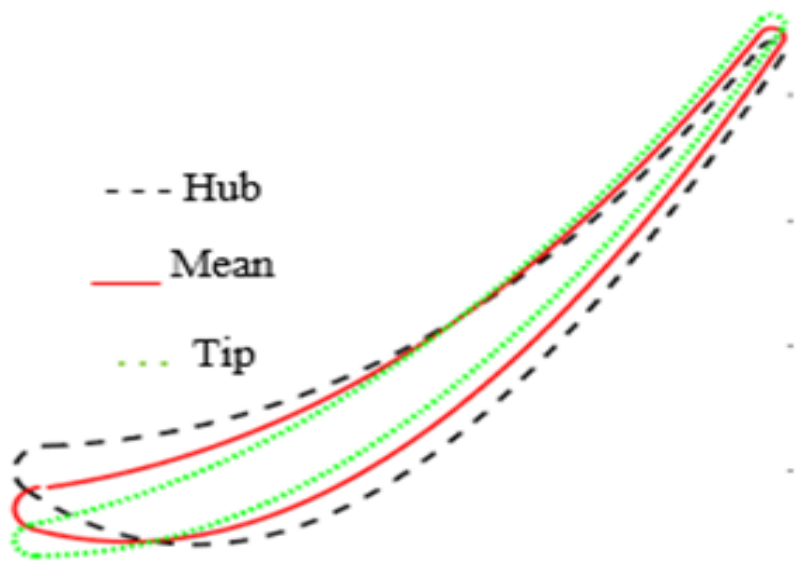

Fig. 7: The generated airfoil sections for rotor blades. 
The axial flow turbine stage aerothermodynamic and geometric data are clarified in Table 3.

Table 3: Turbine stage design data

\begin{tabular}{|c|c|c|c|}
\hline $\begin{array}{l}\text { SI. } \\
\text { NO. }\end{array}$ & Parameter & Units & Value \\
\hline 1 & Turbine work & $\mathrm{J} / \mathrm{kg}$ & 179421.15 \\
\hline 2 & Design point speed $(\mathrm{N})$ & RPM & 110000 \\
\hline 3 & Turbine inlet temp. T_3t & K & 1190 \\
\hline 4 & Mass flow rate & $\mathrm{kg} / \mathrm{s}$ & 0.45 \\
\hline 5 & Flow coefficient & ---- & 0.5 \\
\hline 6 & Loading factor & ---- & 1.14 \\
\hline 7 & Reaction (mean) & --- & 0.39 \\
\hline 8 & Exit relative Mach No. & ---- & 0.78 \\
\hline 9 & Exit Mach No. & ---- & 0.3 \\
\hline 10 & Hub-to-tip ratio & ---- & 0.7 \\
\hline 11 & $\begin{array}{l}\text { Design point } \\
\text { specific speed }\end{array}$ & $N / \sqrt{T_{1 t}}$ & 3188.75 \\
\hline 12 & Normalized mass flow rate & $\frac{m * \sqrt{T_{1 t}}}{P_{1 t}}$ & $4.02^{*} 10^{-5}$ \\
\hline 13 & Exit swirl angle & Degree & 5 \\
\hline 14 & Pitch-to-chord ratio & --- & 0.7 \\
\hline 15 & Total-to-total efficiency & ---- & 0.91 \\
\hline
\end{tabular}

As shown in the previous table, the design methodology satisfies the design constrains and the real engine dimensions using the real operating engine conditions with exit swirl flow velocity of $5^{0}$ which leads to losses minimization ${ }^{[1]}$. The full automation of the method using MATLAB enables the designer to change and repeat the design until obtaining a reliable design.

\section{II.II- Analytical method for axial turbine performance prediction}

In this phase of design, an approximate analytical method is introduced to predict the axial gas turbine performance characteristics at the turbine design point and off-design conditions based on one-dimensional approach with an approximate loss model. Such method is easy to be applied and achieves the gas turbine performance in the preliminary design phase.

For given expansion ratio and isentropic total-to-total efficiency, the turbine work per unit mass is proportional to the inlet stagnation temperature. Since, in addition, the turbine work in the jet engine is commonly two or three times the useful energy output of the engine, a $1 \%$ increase in turbine inlet temperature can produce a $2 \%$ or $3 \%$ increase in engine output. This considerable advantage has supplied the incentive for the adoption of fairly elaborate methods for cooling the turbine nozzle and rotor blades ${ }^{[5]}$.

The gas turbine performance is represented as the relationship between the total to total turbine expansion ratio $\left(\pi_{t t}\right)$ and the normalized mass flow $\left(\mathrm{m} * \sqrt{T_{3 t}} / P_{3 t}\right)$ together with the corresponding total-total isentropic efficiency ${ }^{[8]}$.

The mathematical model is based on the onedimensional performance prediction method at the mean line of the turbine stage. The flow in the axial turbine stage is characterized by a high unsteadiness and three dimensional velocities with random fluctuations due to the interactions between the stationery row and the rotating one ${ }^{[9]}$. Because of this, different losses are created in turbine cascade.

Profile loss is the major losses that are created due to blades boundary layers which will happen through the uniform two-dimensional flow across a cascade of blades. There is the main flow field through the blades flow passage which is described the mean line path of the flow. Overlapping this main flow, a secondary flow field will be produced.

Annulus loss that is created with boundary layer growth on the inner and outer walls of the annulus, is a part of secondary loss.

The tip clearance causes leakage flow across it which disturbs the primary flow. This flow is strongly dependent upon the dimensions of the tip clearance and highly influences the other end wall losses. This flow is ejected as a high-speed jet which mixes with the main stream on the suction side, usually moving down to form a high vortex intensity. This strong jet and vortex cause entropy change ${ }^{[4]}$

II.II.I- Principles of One-Dimensional Analysis in Turbine

As the turbine performance is characterized by obtaining the flow parameters and the pressure loss coefficient, so, the one-dimensional method will be an efficient and fast way for getting the axial flow turbine performance parameters. In this method, the main flow governing equations are solved along the mean line section across the stator and the rotor ${ }^{[5,9]}$.

For ease of manipulation of the flow calculations, some assumptions are taken in consideration.

1. The flow is an ideal gas.

2. The flow is steady.

3. The expansion process is isentropic (reversible and adiabatic).

4. No radial flow velocity.

II.II.II- The methodology of the performance prediction

The proposed one-dimensional method for the axial 
flow turbine performance prediction proceeds as follows:

a) Considering the flow total inlet parameters to the turbine stage obtained from the previous design phases at design point RPM to determine the normalized mass flow parameter at turbine inlet.

b) The total Enthalpy is constant across the stator.

c) The assumed total pressure total pressure recovery factor across the stator is $\sigma=0.99$.

d) As the gas flow velocity across the turbine stage is proportionally related to the turbine expansion ratio, guessing the inlet gas flow velocity will be adequate.

e) Solving the governing equation at the rotor row inlet.

f) Obtaining the rotor exit flow parameters using the energy equation based on Rotalpy conservation with assumed constant relative velocity coefficient $\psi=0.97$.

g) An iteration process is made to evaluate the flow thermodynamic parameters at the rotor exit until the exit mass flow rate equals the inlet one. h) Evaluate the turbine stage total pressure ratio to obtain a point on the turbine characteristics curve.

i) Guessing another gas velocity at the inlet to the rotor and repeating the previous procedure to have another point on the turbine characteristics curve until finishing the design point curve.

i) Select another RPM and calculate the specific speed $N \sqrt{T_{12}}$ and repeat the previous procedure to obtain the characteristics curve at this specific speed.

k) The previous procedure is repeated at different specific speeds to calculate the off-design characteristics curves for any single stage axial flow turbine.

The characteristics curves are calculated at design point, $90 \%, 80 \%, 70 \%$ and $60 \%$ of the design specific speed.

The following flowchart shows the calculations of the design and off-design conditions characteristics of the axial flow turbine with prementioned loss model using the onedimensional mean streamline approach.

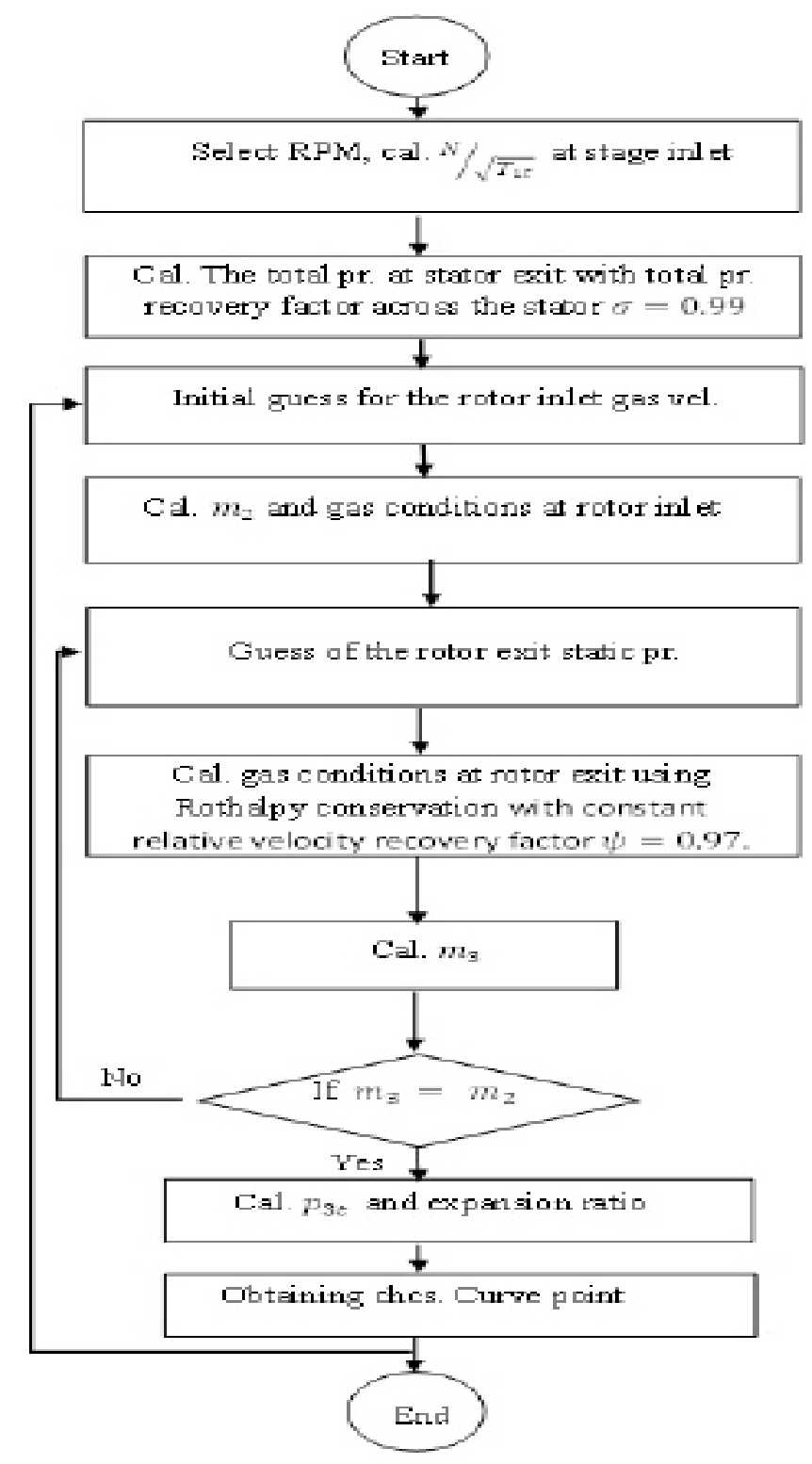

Fig. 8: Turbine stage performance characteristics prediction flow chart. 
The following figures shows the axial flow turbine map curves generated by the MATLAB code based on the one-dimensional mean streamline approach at the design specific speed, $90 \%, 80 \%$ and $70 \%$ and $60 \%$ of the design specific speed. As shown in Fig. (9. a) the operating design point is near chocking.

Fig. 9: Axial flow turbine stage map.

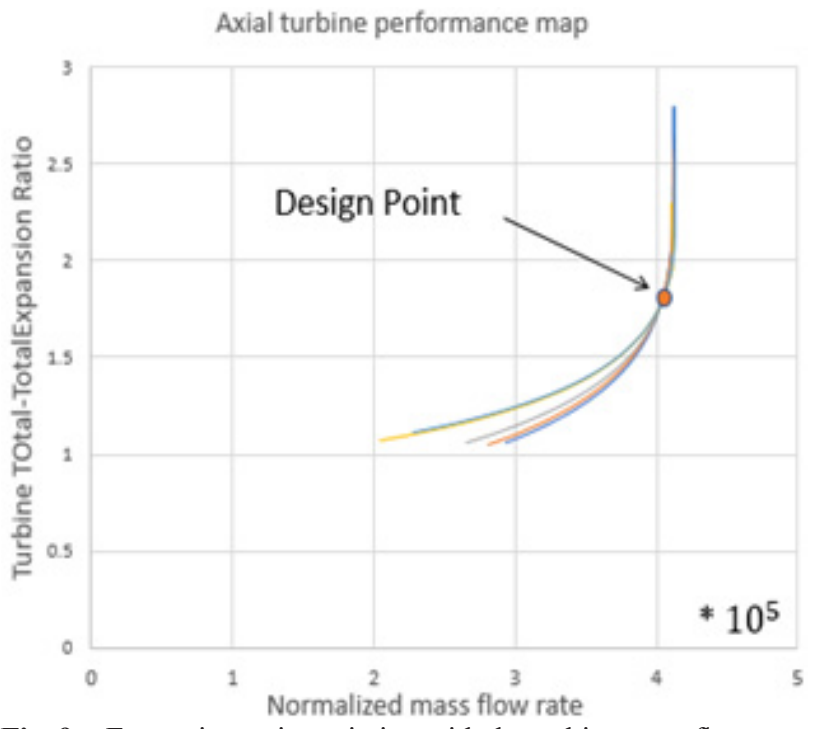

Fig. 9a: Expansion ratio variation with the turbine mass flow rate

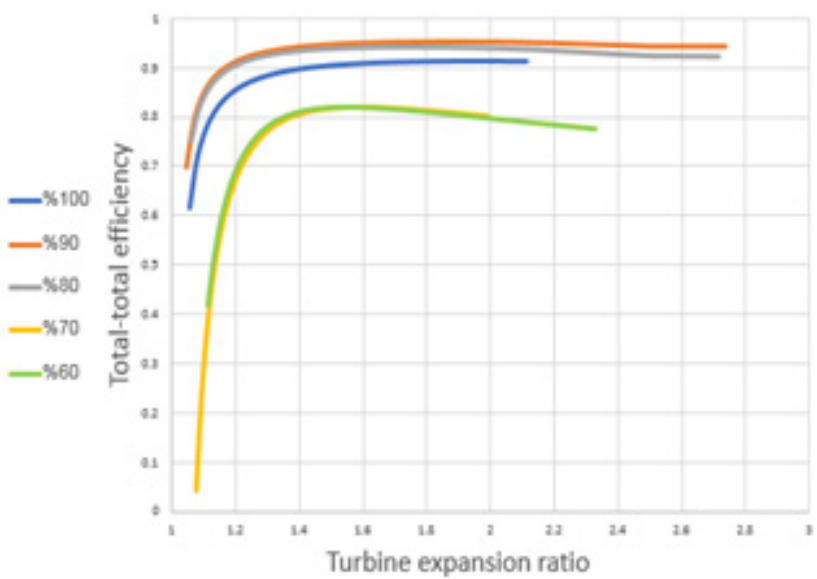

Fig. 9b: Total-Total efficiency variation with turbine expansion ratio

Fig. (9. a) describes the relation between the normalized mass flow rate $\left(m * \sqrt{T_{1 t}} / P_{1 t}\right)$ which behaves as dimensionless group and the turbine expansion ratio $\left(\pi_{t+}\right)$ at the turbine design point and off-design conditions, while Fig. (9. b) shows the variation of the turbine Total-Total thermal efficiency with the total expansion ratio across the turbine at different specific speeds. Both trends shown in Fig. 9 resemble the trends published by Cohen ${ }^{[10]}$.

\section{III- CFD SIMULATION}

In this section, a detail CFD performance analysis is done as the final step in the turbine stage design process. A CFD analysis is used to evaluate the different turbine design parameters by generating the axial turbine stage performance map.

This section describes the definition of the physical parameters to be simulated numerically. The parameters of the flow simulations are then discussed. The computational domains, the well-posed boundary conditions, the computational gridding and the used solver control parameters are clarified, Thereafter, discussing the results of the simulations. Finally, comparing the MATLAB code and CFD results trend and feasibility.

All flow physical simulation conditions of the turbine stage are kept constant at a constant specific speed. The simulation is repeated several times with fixed inlet total conditions and different outlet static pressures where the stage mass flow rate and total-total pressure at the exit section are calculated. The flow mass flow rate and the total inlet and exit pressures are exported to the MATLAB code to draw the characteristics curve generation process. These conditions are chosen to be the same of the flow conditions modelled by the analytical performance method.

\section{III.I- Meshing}

The subprogram meshing Turbogrid integrated in ANSYS is used to discretize the computational domains into cells. The included (ATM optimized) Automatic Topology optimized feature generates a structured hexahedral cell that tracks the surface of the geometry of the blade and is aligned with the direction of the flow. The target number of elements in the mesh is also set. The mesh independence of the flow solutions is checked as shown in Table 5. Fig. 10 shows the structured mesh generated in the rotor domain and nature of the mesh is clearly visible

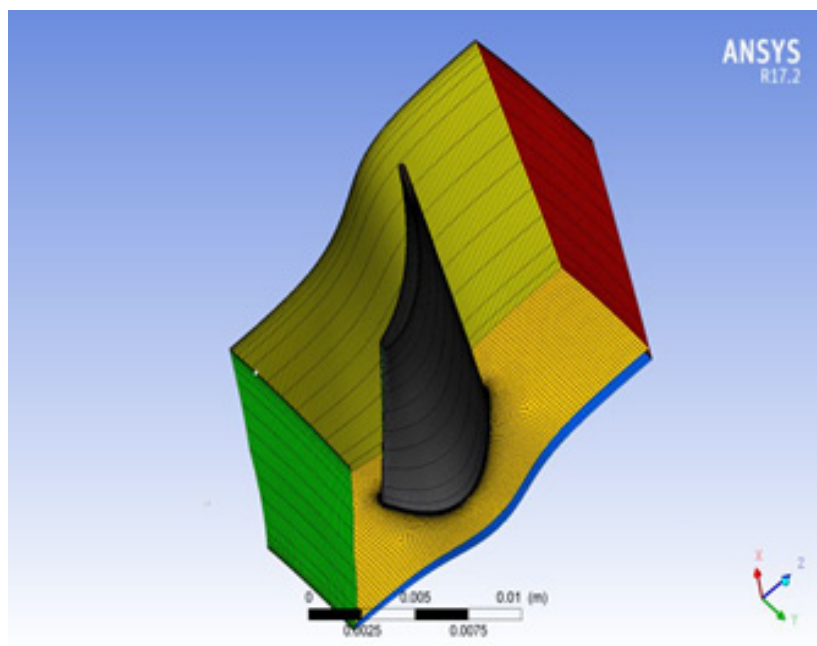

Fig. 10: Meshing of rotor domain.

\section{III.II- Simulation domains}

Simulation of the axial turbine stage is reduced into the passage of one stator blade and one rotor blade cascade. This passage works as a sub-domain of the main domain of the whole turbine to reduce the calculations time and data 
size. The rotor domain rotates at the turbine rotor speed and the stator domain remains stationary. Fig. 12 shows the cascade simulation domains for the turbine CDF model.

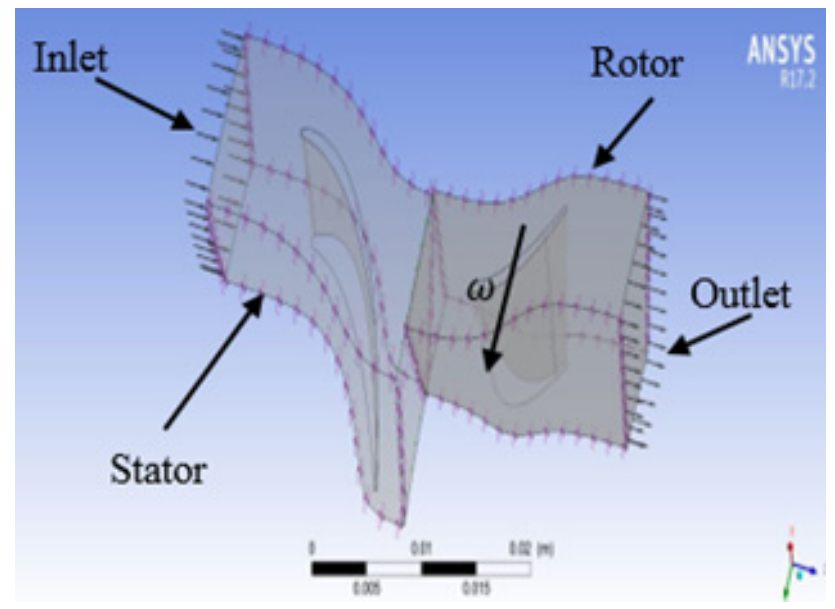

Fig. 12: Rotor and stator domains cascade

\section{III.III- Boundary conditions}

The working fluid is set as ideal gas with well-posed boundary conditions as shown in Table 4:

Table 4: Simulation domains Boundary conditions

\begin{tabular}{lcc}
\hline Feature & Boundary condition & Comment \\
\hline Inlet & $\begin{array}{c}\text { Total pressure and } \\
\text { total temperature }\end{array}$ & Stationery \\
Outlet & Static pressure & Rotating \\
Stator hub & No slip wall & Stationery \\
Rotor hub & No slip wall & Rotating \\
Stator shroud & No slip wall & Stationery \\
Rotor shroud & No slip wall & Rotating \\
Interface & Frozen rotor & Constant total \\
Stator blade wall & No slip wall & Stationery \\
Rotor blade wall & No slip wall & Rotating \\
\hline
\end{tabular}

The rotor blade and hub surface are all chosen as no-slip walls. The rotor shroud is chosen as a counter rotating wall, to take in consideration the effect of the stagnant shroud in the rotating domain. The interface between both stator and rotor domains is chosen as total pressure conservation, known as a frozen rotor interface. Therefore, frozen rotor interfaces are used between these domains. The inlet boundary conditions are set as the total pressure and total temperature. The outlet is chosen as a static pressure specification. These boundary conditions for the two computational domains are demonstrated in Fig. 13. a, b.

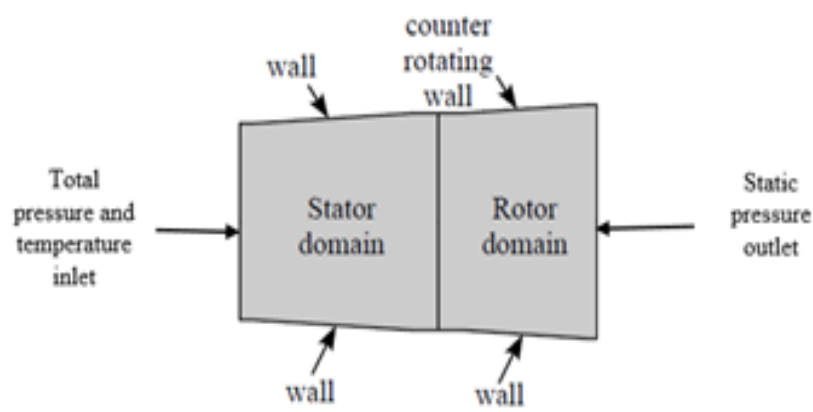

Fig. 13.a: Boundary conditions definitions in meridional plane.

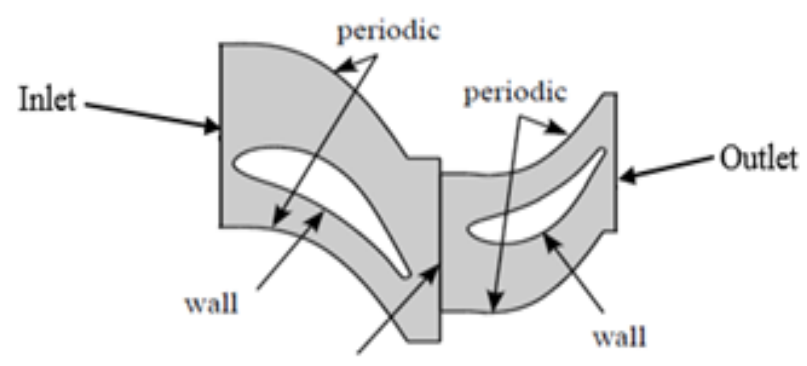

Frozen rotor

Fig. 13. b: Boundary conditions definitions in blade- blade plane.

As recommended in turbomachinery simulation, the flow is modelled as three dimensional, steady, turbulent, compressible and viscous flow with $\mathrm{k}-\omega$ turbulence model.

Mesh independence study is made to ensure that the results are independent on the mesh intensity, Table 5. Table 5 shows the data of the mesh independent study.

Table 5: Mesh independent data

\begin{tabular}{lcc}
\hline $\begin{array}{l}\text { Number of } \\
\text { mesh element }\end{array}$ & Mass flow rate & $\begin{array}{c}\text { Total-to-total } \\
\text { efficiency }\end{array}$ \\
\hline 222051 & 0.4325 & $\% 90.48$ \\
423176 & 0.4465 & $\% 91.82$ \\
635842 & 0.448 & $\% 91.8301$ \\
\hline
\end{tabular}

Separate simulation models are constructed for different mesh element number in each domain $(100,000$ elements, 200,000 elements and 300,000 elements) gives the mentioned data in the table for both domains. As shown in Table 4, the change of the elements number affects slightly the simulation results, so, the model of 200,000 elements for each domain is chosen as it achieves good results and reduces the run time.

\section{III.IV- CFD turbine stage performance map}

The target of this section is to generate the turbine stage performance map by obtaining points on the performance curve using CFD work.

At constant specific speed, ANSYS run is done at 
certain Inlet total pressure and temperature and certain exit static pressure. Such run is repeated several times by keeping the inlet total parameters and changing the exit static pressure by a static pressure difference step equals 0.2 to generate the performance curve at certain specific speed.

Change the running specific speed and repeat the previous procedure to generate the off-design performance curves.

\section{IV- RESULTS AND DISCUSSION}

Fig. 14 shows a set of graphs illustrating the variation of the expansion ratio for the turbine stage with the normalized mass flow rate at different specific speeds generated from both the analytical and the CFD methods.

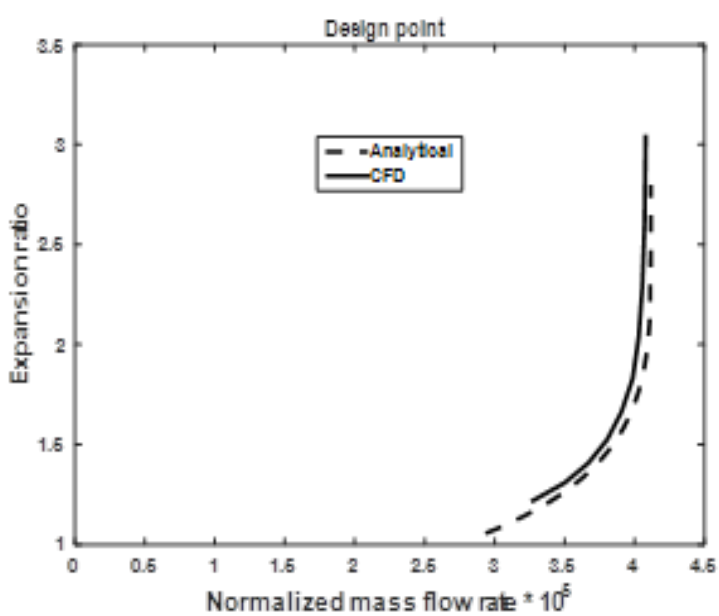

(a)

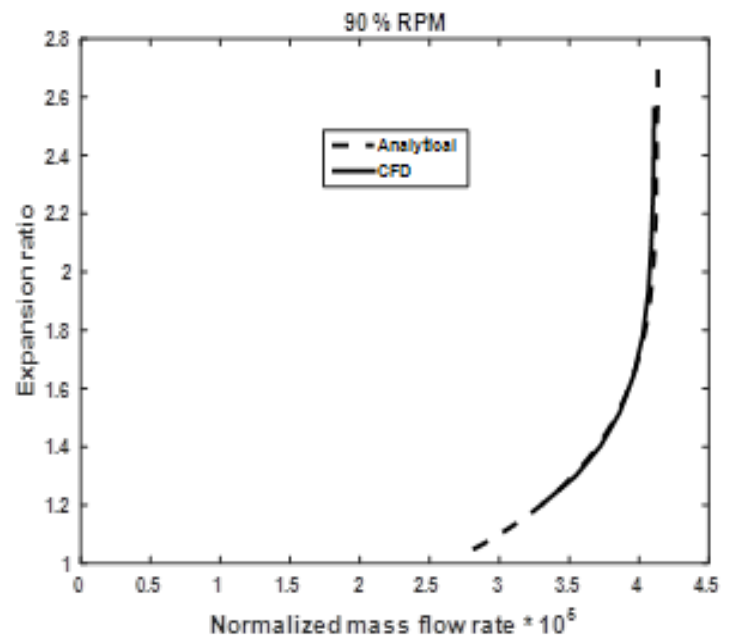

(b)

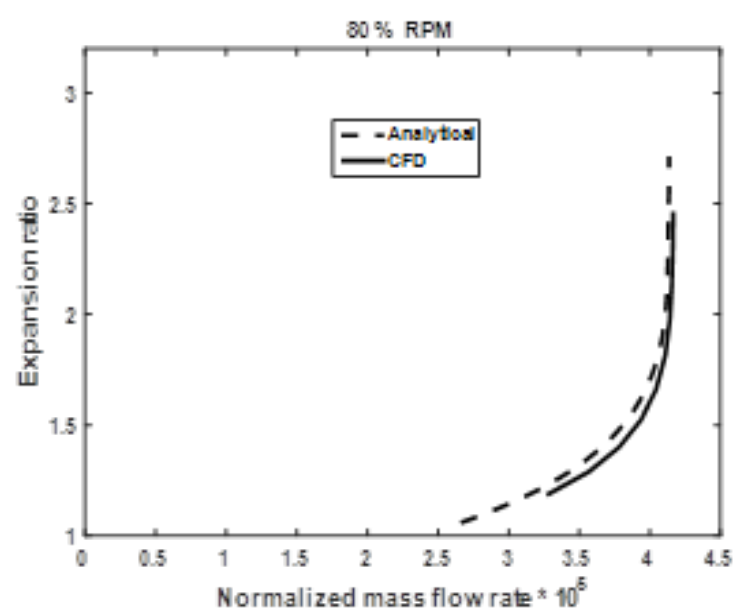

(c)

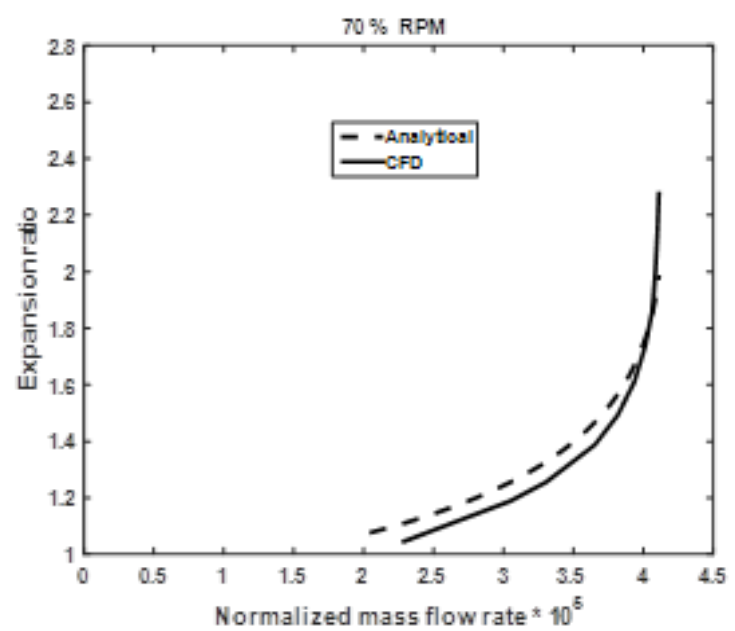

(d)

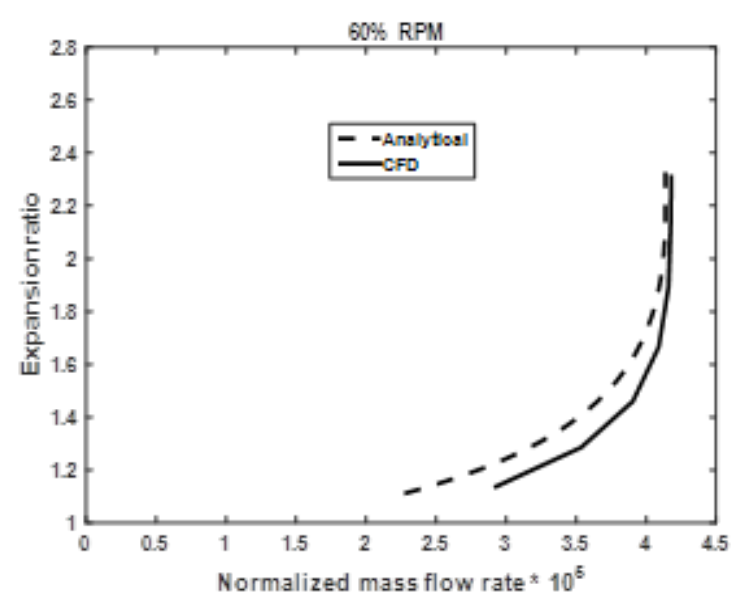

(e)

Fig. 14: Analytical and CFD axial turbine stage characteristics comparison. 
While fig. 15 shows two graphs illustrating the variation of the turbine total-total isentropic efficiency with the turbine stage expansion ratio at the design speed and $60 \%$ specific speed.

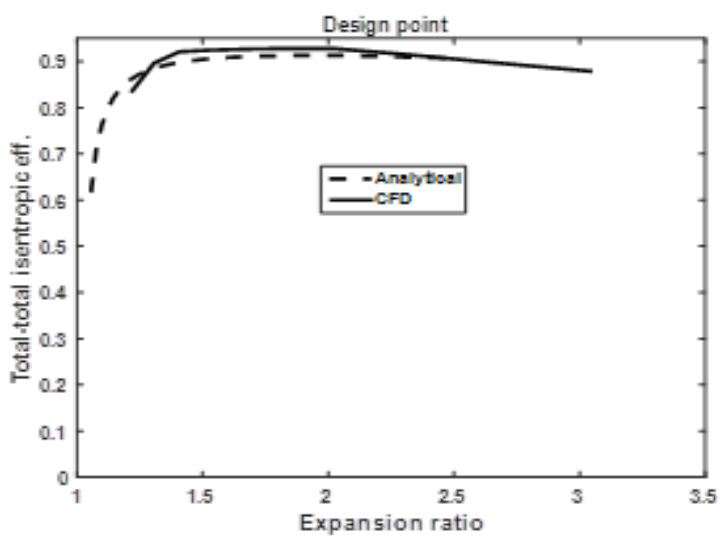

(a)

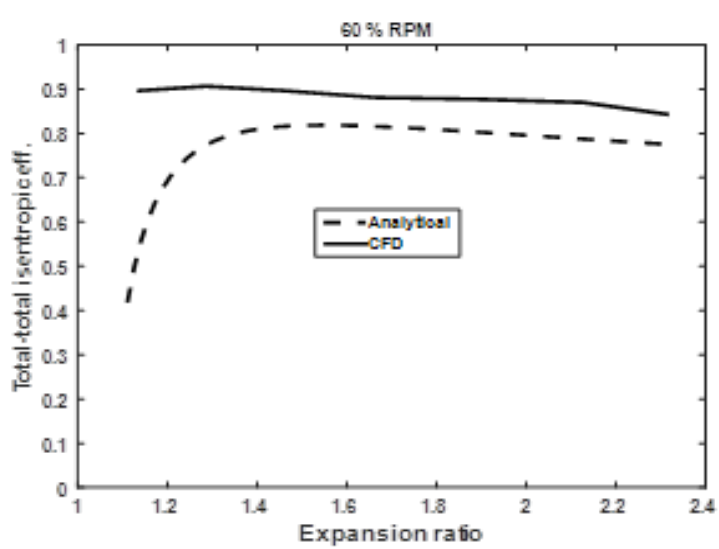

(b)

Fig. 15: Analytical and CFD axial turbine characteristics comparison.

\section{V- CONCLUSIONS}

An automated implicit and robust method for an axial gas turbine stage design and analysis that controlled by the design parameters is constructed. Flexible and accurate as to be used efficiently in the preliminary design phase. The flexibility of the method is measured by reproducing several turbine designs with different designer requirements. The generated designs gave good thermal efficiency compared with the recent publications. The final required design gave thermal efficiency of $91 \%$ and average exit swirl velocity of $\mp 5^{0}$ deviation from the axial direction which minimizes the losses at turbine stage exit.

Complete demonstration for preliminary design method for single stage axial flow turbine is presented in this research.

CFD model is constructed using the real working conditions of the engine as the boundary conditions to evaluate the behavior of the flow through the turbine stage.

The turbine map generated numerically using ANSYS CFX. A comparison between the resulted data from both analytical and numerical methods is made.

The CFD results shows a good match with that of the analytical method at design point and at \% 90 specific speed ratio with slight deviation at smaller specific speed ratios due to the assumed constant losses values for both stator and rotor rows.

The presented method is acceptable for the preliminary design of the axial flow turbine but not enough for the detailed design, therefore, the turbine losses should be calculated using the loss model proposed by Ainley, Mathiesen $^{[11]}$, Dunham and Came ${ }^{[12]}$ and improved by Kacker and Okapuu ${ }^{[13]}$, Moustapha, Kacker and Tremblay ${ }^{[14]}$.

\section{VI- REFERENCES}

[1] Kumar, K., R. Prathapanayaka., "Design and Analysis of a High Pressure Turbine Using Computational Methods for Small Gas Turbine Application," in ASME 2013 Gas Turbine India Conference, 2013, pp. V001T02A009-V001T02A009.

[2] Aly M. Elzahaby., "Detailed design for axial flow turbine stage with drawing," Printed lectures, 20152015.

[3] Jetcat, "Germany, J., "Jetcat products/turbojets/P200. Jetcat Germany. [Online] ", ed.," 20092009.

[4] Dixon, S. L. and Hall, C., Fluid mechanics and thermodynamics of turbomachinery: Butterworth-Heinemann, 2013.

[5] Hill, P. G. and Peterson, C. R., "Mechanics and thermodynamics of propulsion," Reading, MA, Addison-Wesley Publishing Co., 1992, 764 p., 1992.

[6] Lyche, T. and Morken, K., "Spline methods draft," Department of Informatics, Center of Mathematics for Applications, University of Oslo, Oslo, 2008.

[7] Elqussas, N., Aly M. Elzahaby, Mohamed K. Khalil, A. M. Elshabka "AUTOMATION OF DESIGN TOOL FOR AN AXIAL FLOW GAS TURBINE STAGE USED IN SMALL GAS TURBINE ENGINE," presented at the AEROSPACE SCIENCES \& AVIATION TECHNOLOGY, April - 2017, ASAT - 17 - asat@mtc.edu.eg, Military Technical College, Cairo, EGYPT, 2017.

[8] Horlock, J. H., Axial flow turbines: fluid mechanics and thermodynamics: Krieger Pub Co, 1973.

[9] Jouybari, J., et al., "Analytical modeling of performance characteristics of axial flow two-stage turbine engine using pressure losses models and comparing with experimental results," 2013.

[10] H. Cohen, Saravanamuttoo, H. I. H., et al., Gas turbine theory: Pearson Education, 2001.

[11] Ainley, D. and Mathieson, G. C., "A method of performance estimation for axial-flow turbines," AERONAUTICAL RESEARCH COUNCIL LONDON (UNITED KINGDOM)1951.

[12] Dunham, J. and Came, P., "Improvements to the Ainley-Mathieson method of turbine performance prediction," ASME paper, 1970.

[13] S. C. Kacker, Okapuu, U., "A mean line prediction method for axial flow turbine efficiency," Journal of Engineering for Power JANUARY1982, vol. 104, p. 111, 1982.

[14] S. H. Moustapha, S. C. Kacker, Tremblay, B., "An improved incidence losses prediction method for turbine airfoils," Journal of Turbomachinery, vol. 112, p. 267, 1990. 